\section{Commentary: Ode to the editorial process: Health care disparities unmasked}

\author{
Natalie Jayaram, MD, MSB, \\ Brett R. Anderson, MD, MBA, MS, ${ }^{\mathrm{b}}$ and \\ Tara Karamlou, MD, $\mathrm{MSc}^{\mathrm{c}}$
}

Recent events in our nation highlight the need to move issues regarding race and ethnicity to the forefront of our discussions and call on us to acknowledge and act on the inequities that exist for patients of color. Although many would like to believe that medicine-and particularly pediatric subspecialty care-is immune to the inequalities that exist outside the doors of our hospitals, the literature abounds with examples of disparities in health outcomes by race, ethnicity, language, and socioeconomic status (SES). As a health care community we must examine ways to minimize these disparities. The first step in this process is recognizing the scope of these inequalities as a means to further our collective understanding of the primary drivers and to inform mitigating initiatives.

Tjoeng and colleagues ${ }^{1}$ use the Virtual Pediatric Systems (72 institutions with $85 \%$ complete race/ethnicity data) to examine association between race/ethnicity and mortality following pediatric cardiac surgery over a 7year period. ${ }^{1}$ The authors report that, among patients admitted immediately following cardiac surgery, black race was associated with both increased severity of illness on admission and in-hospital mortality, and that the association between race and mortality was attenuated after adjusting for severity of illness. In their study, race was

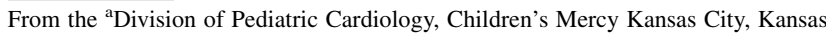
City, Mo; ${ }^{b}$ Division of Pediatric Cardiology, NewYork-Presbyterian/Columbia University Irving Medical Center, New York, NY; and ${ }^{\mathrm{c}}$ Division of Pediatric Cardiac Surgery and the Heart, Vascular, and Thoracic Institute, Cleveland Clinic, Cleveland, Ohio.

Disclosures: The authors reported no conflicts of interest.

The Journal policy requires editors and reviewers to disclose conflicts of interest and to decline handling or reviewing manuscripts for which they may have a conflict of interest. The editors and reviewers of this article have no conflicts of interest.

Received for publication July 6, 2020; revisions received July 6, 2020; accepted for publication July 7, 2020; available ahead of print July 13, 2020.

Address for reprints: Tara Karamlou, MD, MSc, Division of Pediatric Cardiac Surgery, Cleveland Clinic, 9500 Euclid Ave, M41-022A, Cleveland, OH 44120 (E-mail: karamlt@ccf.org).

J Thorac Cardiovasc Surg 2020;160:1580-1

$0022-5223 / \$ 36.00$

Copyright (c) 2020 by The American Association for Thoracic Surgery

https://doi.org/10.1016/j.jtcvs.2020.07.021

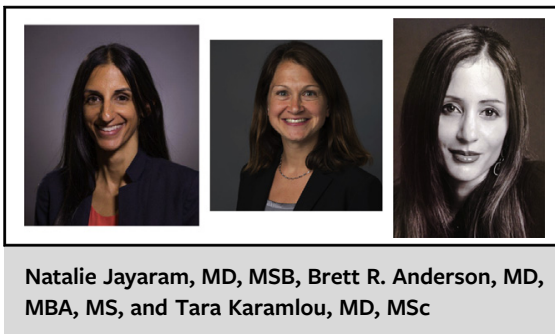

CENTRAL MESSAGE

Iterative evolution of truth:

Highlighting the importance of associations between illness

severity and socioeconomic/race

factors is a critical step forward.

not significantly associated with mortality among patients admitted preoperatively, although less than one-fourth of the population was in the preoperative admission cohort. Possible factors underlying the mitigating influence of preoperative admission postulated by the authors were increased access to diagnostics and therapies and additional inpatient time to recover before surgery. Whether the artificial separation of the study cohort into preoperative and postoperative groups is a valid dichotomy that furthers understanding of the disparity issues remains an open question.

It is worth mentioning that the conclusions of the current article are quite different from those articulated in the initial submission-and much more reflective of truth. As such, this article is not only an important contribution to our understanding of motivating and modifying factors in the health care disparity equation, but a shining example of the virtues of an iterative editorial process when embraced by a responsive investigative team.

The findings of this study by Tjoeng and colleagues ${ }^{1}$ affirm the notion that differences in disease severity may drive health inequities. ${ }^{2,3}$ Yet this study raises as many questions as it provides answers, highlighting the continued gaps in our knowledge. Perhaps, as hypothesized by the authors, delays in detection of congenital heart disease and limited access to subspecialty service are contributing to greater illness severity and driving the association between race and mortality. Although the authors note no differences in timing of surgery among the preoperative admission group, differences in thresholds for surgical referral, timing of surgery, or other aspects of preoperative 
care likely increase illness severity among the postadmission group.

The higher disease severity among black patients in this study is complex and multifactorial and may include social and structural determinants of health, economic disadvantage, and limitations in access to care, as well as implicit and explicit biases. Only after factors responsible for greater disease severity among black patients are more completely understood, can a multifaceted approach to address, mitigate, and eliminate such disparities be developed.

One critical and missing piece from the study that could help illuminate the observed association between race, disease severity, and outcomes is lack of socioeconomic data. Lower SES has the potential to limit access to subspecialty service, create transportation barriers to keeping follow-up appointments, or lead to food insecurity affecting underlying nutritional status, among other factors. Given the current climate that encourages virtual visitation and telehealth, access to reliable Internet services and electronic equipment are also factors that may unmask SES-related access disparities. In general, minorities are disproportionately likely to have lower SES and prior studies have highlighted disparities in outcomes for congenital heart disease patients based on SES. ${ }^{2,4}$ Furthermore, whereas prior studies have demonstrated that whereas race/ethnicity, household, and neighborhood socioeconomic factors all contribute independently to inequities in patient outcomes, SES also explains significant portions of the associations between race/ethnicity and outcomes. ${ }^{2,5}$ Guidelines for study of race and ethnicity in biomedical publications urge scientists to adjust for conceptually relevant measures of SES because "lack of adjustment for SES is the most important potential source of bias in study of racial/ethnic differences." Thus, a natural next step for the current study ${ }^{1}$ would be to determine whether inclusion of SES modifies the study findings.

The merit of the work by Tjoeng and colleagues, ${ }^{1}$ reminiscent of the subject matter, is multifaceted. It is preternaturally timely, reveals yet another promising avenue in which to drive health care disparity mitigation, and unequivocally demonstrates the virtues of the iterative evolution of truth-a process that, as Thareja and colleagues ${ }^{7}$ describe, "transforms complexity into simplicity and simplicity into newer complexity." We could not have said it better ourselves.

\section{References}

1. Tjoeng YL, Jenkins K, Deen JF, Chan T. Association between race/ethnicity, illness severity, and mortality in children undergoing cardiac surgery. J Thorac Cardiovasc Surg. 2020;160:1570-9.e1.

2. Anderson BR, Fieldston ES, Newburger JW, Bacha EA, Glied SA. Disparities in outcomes and resource use after hospitalization for cardiac surgery by neighborhood income. Pediatrics. 2018;141:e20172432.

3. Fixler DE, Xu P, Nembhard WN, Ethen MK, Canfield MA. Age at referra and mortality from critical congenital heart disease. Pediatrics. 2014;134: e98-105.

4. Bucholz EM, Sleeper LA, Newburger JW. Neighborhood socioeconomic status and outcomes following the Norwood procedure: an analysis of the Pediatric Heart Network Single Ventricle Reconstruction Trial public data set. J Am Heart Assoc. 2018;7:e007065.

5. Peyvandi S, Baer RJ, Moon-Grady AJ, Oltman SP, Chambers CD, Norton ME et al. Socioeconomic mediators of racial and ethnic disparities in congenital heart disease outcomes: a population-based study in California. J Am Heart Assoc. 2018; 7:e010342.

6. Kaplan JB, Bennett T. Use of race and ethnicity in biomedical publication. JAMA 2003;289:2709-16

7. Thareja P, Sharma K, Sharma S, Kaur J, Singh A. Innovaluation: the skill for make in India initiative in IOT era. Trends Mech Engineer Technol. 2016;6:26-40. 